\title{
Pattern of Neuropsychiatric Disorders in Geriatric Patients Attending Psychiatry Facility in a Tertiary Care
}

\author{
Senilo Magh ${ }^{1}$, Sahana N ${ }^{2}$, L. Chingkheileima ${ }^{3}$, Rajkumar Lenin Singh ${ }^{4}$ \\ 1,2,3- Junior Residents, ${ }^{4-}$ Professor \\ Regional Institute Of Medical Sciences, Imphal, Manipur, India
}

\begin{abstract}
Background: 8\% of India's population is above 60 years of age warranting an institution based study of patterns of neuropsychiatric disorders in elderly psychiatry outpatients.

Objectives: to document the profile of neuropsychiatric disorders and physical co-morbidities among geriatric patients.

Material And Method: This was a retrospective chart review of OPD records of all patients of age 60 years and above who attended RIMS Psychiatry OPD between Jan 2012 and Sept 2016.

Result: A total of 4076 geriatric patients attended the Psychiatry OPD during the study period. Mean age was 67.53 years Age ranged from 60-98 years, 63.7\% ( $n=1380)$ belonged to the age group of 60-69 years and $53.2 \%(n=2168)$ were male. $98.3 \%(n=4006)$ were found to have neuropsychiatric disorder. Overall, mood disorders (29.8\%) was found to be the most common neuropsychiatric disorder with depression itself accounting for $25.6 \%$ of study population, followed by generalized anxiety disorder (17.42\%), dementia (15.5\%) and substance use disorders (5.3\%). Comorbid physical illness was found in $10.2 \%$ of the patients with hypertension being the commonest (28.0\%).
\end{abstract}

Conclusion: the majority of geriatric patients belonged to the age group of 60-69 years and the most common disorders were depression, generalized anxiety disorder, dementia and substance use disorders

Keywords: geriatric, mood disorder, generalised anxiety disorder.

\section{Introduction}

Elderly or old age consists of ages nearing or surpassing the average life span of human beings. There is no exact definition of old-age but the National Policy on Older Persons 1999, defines 'senior citizen' or 'elderly' as a person who is of age 60 years or above. ${ }^{1}$ Although they are referred to as the dependent population, they form an integral part of a community with immense values and knowledge to offer. WHO has adopted $1^{\text {st }}$ October as the international day of older persons in order to raise awareness about the problems faced by older people and their contribution to the society. ${ }^{2}$

The 2011 census showed that $8 \%$ of Indian population is made up of people aged 60 years and above (5.3\% > 65 years). ${ }^{3}$ The United Nations Population Division predicts that this figure will rise to $19 \%$ by $2050 .{ }^{4}$ Globally, life expectancy at birth is projected to rise from 70 years in 2010-2015 to 77 years in 204-52050 and to 83 years in 2095-2100. The number of persons aged 60 and above is expected to more than double by 2050 and more than triple by 2100, increasing from 901 million in 2015 to 2.1 billion in 2050 and 3.2 billion in $2100 .^{5}$ Sufficient resources need to be employed to cater to health care needs of the geriatric population, especially when it is evident that they are more vulnerable to physical and mental illness. The psychiatric morbidity is much higher in the geriatric population as compared to the non-geriatric population as shown in a study by Tiwari et al According to two different studies by Tiwari et al and Seby et al, prevalence of psychiatric illness in elderly persons of the general population in the rural and urban settings were $23.7 \%$ and $26.7 \%$ respectively. ${ }^{7,8}$ High prevalence of psychiatric co-morbidity ranging from $45 \%$ to $62 \%$ has been documented in non-psychiatric elderly medical inpatients in many studies indicating the need for active surveillance for psychiatric morbidity and better management of the elderly patients Singh et al documented physical illness in $48 \%$ psychiatric out-patients and Nandi et al found $41.9 \%$ of the mentally ill persons were also physically ill with most having more than one physical illness. The increased burden of physical illness in elderly patients with psychiatric illness warrants higher vigilance in clinical practice in order to improve their quality of lifeThis hospital based study aims to determine the pattern of psychiatric morbidity and physical co-morbidity among geriatric patients attending Psychiatry outpatient department of a tertiary care hospital in an urban area.

\section{Materials And Methods}

The study was conducted in the Department of Psychiatry, Regional Institute of Medical Sciences Hospital, Imphal, Manipur. A chart review of case record of all geriatric patients aged 60 years and above attending Psychiatry Out-patient Department(OPD) from January 2012 to September 2016 was carried out and 
socio-demographic variables; age, sex, district, neuropsychiatric diagnosis and physical co-morbidities were documented for the study. Data was analyzed was using the Statistical Package for Social Sciences, SPSS for windows version 21 .

\section{Results}

A total of 4076 geriatric patients attended Psychiatry OPD during the study period. Fig. 1 shows the demographic details. The patients' age ranged from 60 to 98 years (mean age $=67.53$ years). Majority belonged to the age group of $60-69$ years, $63.7 \%(n=1380)$ and $53.2 \%$ were male, $(n=2168)$.

\begin{tabular}{|l|l|l|l|}
\hline Category & Variables & Frequency & Percentage \\
\hline \multirow{3}{*}{$\begin{array}{l}\text { Age group } \\
\text { years) }\end{array}$} & $60-69$ & 2596 & 63.7 \\
\cline { 2 - 4 } & $70-79$ & 1154 & 28.3 \\
\cline { 2 - 4 } & $80-89$ & 265 & 6.5 \\
\cline { 2 - 4 } & 90 and above & 61 & 1.5 \\
\hline \multirow{3}{*}{ Sex } & Male & 2168 & 53.2 \\
\cline { 2 - 4 } & Female & 1908 & 46.8 \\
\hline \multirow{3}{*}{ Religion } & Hindu & 3524 & 86.4 \\
\cline { 2 - 4 } & Christian & 327 & 8 \\
\cline { 2 - 4 } & Muslim & 225 & 5.5 \\
\hline
\end{tabular}

Fig. 1: socio-demographic distribution

Out of 4076 patients who attended the OPD, 4006 were found to have neuropsychiatric disorder (98.3\%). Fig. 2 shows the pattern of neuropsychiatric disorders.

\begin{tabular}{|l|ll|}
\hline \multicolumn{1}{|c|}{ Diagnosis } & \multicolumn{2}{c|}{ Percentage } \\
\hline Mood disorders & $29.8 \%$ & $(\mathrm{n}=1212)$ \\
\hline Anxiety disorders & $23.1 \%$ & $(\mathrm{n}=941)$ \\
\hline Dementia & $15.5 \% \quad(\mathrm{n}=631)$ \\
\hline Physical Comorbidities & $10.2 \% \quad(\mathrm{n}=416)$ \\
\hline Schizophrenia and other psychotic disorders & $9.9 \% \quad(\mathrm{n}=404)$ \\
\hline Substance use disorders & $5.3 \%$ & $(\mathrm{n}=216)$ \\
\hline Somatoform disorders & $2.8 \%$ & $(\mathrm{n}=114)$ \\
\hline No psychopathology detected & $1.7 \%$ & $(\mathrm{n}=70)$ \\
\hline Sleep disorders & $1 \%$ & $(\mathrm{n}=40)$ \\
\hline Stress related disorders & $0.4 \%$ & $(\mathrm{n}=16)$ \\
\hline Other psychiatric disorders & $0.4 \%$ & $(\mathrm{n}=16)$ \\
\hline
\end{tabular}

Fig. 2: Neuropsychiatric disorders of old age

$29.8 \%$ of total patients $(n=1214)$ were diagnosed with mood disorder (female $51 \%$; male $49 \%$ ). Depression was diagnosed in $25.6 \%$ of patients. $23.1 \%$ of total patients $(n=942)$ had anxiety disorder with $17.4 \%$ diagnosed as generalized anxiety disorder $(n=710$; female $54 \%$; male $46 \%)$. Dementia was found in $15.5 \%$ of total patients $(n=630$; male $56.8 \%$; female $27.1 \%)$. Substance use disorder was diagnosed in $5.3 \%$ of total patients $(n=318)$.

\begin{tabular}{|l|ll|}
\hline Substance & \multicolumn{2}{|l|}{ Percentage } \\
\hline Alcohol & $95.3 \%$ & $(\mathrm{n}=204)$ \\
\hline Cannabis & $1.9 \%$ & $(\mathrm{n}=3)$ \\
\hline Nicotine & $1.9 \%$ & $(\mathrm{n}=4)$ \\
\hline Opioid & $1.9 \%$ & $(\mathrm{n}=3)$ \\
\hline Benzodiazepine & $0.9 \%$ & $(\mathrm{n}=2)$ \\
\hline
\end{tabular}

Fig. 3: Type of substance use in old age

Fig. 3 showed the types and prevalence of substance use disorders. 9.4\% of total males $(n=204)$ and $0.7 \%$ of total females $(\mathrm{n}=14)$ had substance use disorder.

\begin{tabular}{|l|ll|}
\hline Disease & \multicolumn{2}{|l|}{ Percentage } \\
\hline Hypertension & $28.0 \%$ & $(\mathrm{n}=117)$ \\
\hline Parkinsons disease & $24.6 \%$ & $(\mathrm{n}=103)$ \\
\hline Cerebrovascular accident & $17.9 \%$ & $(\mathrm{n}=74)$ \\
\hline Diabetes mellitus & $15.0 \%$ & $(\mathrm{n}=62)$ \\
\hline Others & $6.3 \%$ & $(\mathrm{n}=26)$ \\
\hline Seizure disorder & $5.8 \%$ & $(\mathrm{n}=24)$ \\
\hline Respiratory diseases & $2.4 \%$ & $(\mathrm{n}=10)$ \\
\hline
\end{tabular}

Fig. 4: Physical illness of old age 
Pattern Of Neuropsychiatric Disorders In Geriatric Patients Attending Psychiatry Facility In ...

$10.2 \%$ of total patients $(n=414$; male $72.9 \%$; female $27.1 \%)$ had physical co-morbidities. Fig.4 shows the prevalence of specific co-morbidities.

\section{Discussion}

98.6\% of persons who attended the psychiatry OPD were found to have psychiatric illness. Mood disorder was the most common neuro-psychiatric disorder $(29.8 \%)$ which is at par with other studies by Tiwari SC, Seby K and Aich TKDepression alone was diagnosed in $25.6 \%$ of the study population similar with studies from Sood A and Tiple PAnxiety disorder was diagnosed in $23.1 \%$ of patients which is at par with report of $20.38 \%$ and $8.69 \%$ from Tiwari SC and Tiple P respectively. ${ }^{6,16}$ Generalised anxiety disorder alone was diagnosed in $17.4 \%$ of patients with a slight female preponderance. Dementia accounted for $15.5 \%$ in this study similar with reports from Seby K of $14.9 \%$ Comorbid physical illness was found in $10.2 \%$ of the patients with hypertension being the commonest $(28.0 \%)$ followed by Parkinsons disease $(24.6 \%)$ and stroke $(17.9 \%)$ at par with other studies (Singh GP, Tiple P) Substance use disorder was diagnosed in $5.3 \%$ of the patients, much higher in males $(9.4 \%)$ compared to females $(0.7 \%)$. Alcohol was the most common substance abused $(95.3 \%)$, consistent with other studies (Singh GP, Tiple P)

\section{Limitations}

These findings have to be taken with consideration that this is a retrospective chart review study. In addition, this study is limited to a tertiary hospital based in an urban area and hence cannot be generalized.

\section{Conclusion}

Clinicians need to be more vigilant to rule out depression, anxiety and dementia in geriatric patients. The increasing trend in the number of geriatric patients with neuropsychiatric disorders warrants a better healthcare and social support. Substance use disorders continues to be a problem in geriatric population. High physical comorbidities in this age group calls for a conscious, consorted multi-disciplinary approach.

\section{References}

[1]. Central Statistics Office, Ministry of Statistics \& Programme Implementation, Government of India; Situation analysis of the elderly in India. New Delhi: Ministry of Statistics \& Programme Implementation; 2011.

[2]. World Health Organisation. Accessed at http://www.who.int/ageing/events/idop_rationale/en/ on 24.01.2017.

[3]. Census 2011. Office of the Registrar General and Census Commissioner. New Delhi: Government of India; 2011.

[4]. Population Reference Bureau. Today's research on ageing. Washington DC: Population Reference Bureau; $2012: 25$.

[5]. UN population Division: World population prospects, the 2015 revision. New York: United Nations publication 2015.

[6]. Tiwari SC, Srivastava Shrikant. Geropsychiatric morbidity in rural Uttar Pradesh. Indian J Psychiatry 1998:40(3);266-73.

[7]. Tiwari SC, Srivastava G, Tripathi RK, Pandey NM, Agarwal GG, Pandey S, et al. Prevalence of psychiatric morbidity amongst the community dwelling rural older adults in northern India. Indian J Med Res 2013:138;504-14.

[8]. Seby K, Chaudhary S, Chakraborty R. Prevalence of psychiatric and physical morbidity in an urban geriatric population. Indian J Psychiatry 2011:53(2)

[9]. Uwakwe R. Psychiatric morbidity in elderly patients admitted to non-psychiatric wards in a general/teaching hospital in Nigeria. Int J Geriatr Psychiatry 2000;15:346-54.

[10]. Bowler C, Boyle A, Branford M, et al. Detection of psychiatric disorders in elderly medical in-patients. Age Ageing 1994;23:30711.

[11]. Sood A, Singh P, Gargi PD. Psychiatric morbidity in non-psychiatric geriatric inpatients. Indian J Psychiatry 2006;48:56-61.

[12]. Muller TT, Meins W, Manecke S. Psychiatric disorders in the elderly and psychosocial background. A study of geriatric inpatients. Psychiatr Prax 1999;26:267-72.

[13]. Singh GP, Chavan BS, Kaur P, Bhatia S. Physical illnesses among psychiatric outpatients in a tertiary care health institution: A prospective study. Indian J Psychiatry 2006;48:52-5.

[14]. Nandi PS, Banerjee G, Mukherjee SP, Nandi S, Nandi DN. A study of psychiatric morbidity of the elderly population of a rural community in West Bengal. Indian J Psychiat 1997;39(2):122-9.

[15]. Aich TK, Dhungana M, Muthuswamy R. Pattern of neuropsychiatric illnesses in older age group population: An inpatient study report from Nepal. Indian J Psychiatry 2012;54(1):23-31.

[16]. Tiple P, Sharma SN, Srivastava AS. Psychiatric morbidity in geriatric people. Indian J Psychiatry 2006;48:88-94. 